\title{
Relação energia metabolizável: aminoácidos sulfurosos para aves leves nas fases de crescimento
}

Metabolizable energy: sulfurous amino acids ratio for light laying hens in the growth stages

Relación de energía metabolizable: aminoácidos sulfurosos para gallinas ponedoras ligeras en etapa de crecimiento

Sarah Gomes Pinheiro

ORCID: https://orcid.org/0000-0002-8577-3576

Universidade Federal da Paraíba, Brasil

E-mail: sarahgpzootecnista@gmail.com

Fernando Guilherme Perazzo Costa

ORCID: https://orcid.org/0000-0003-4075-1792

Universidade Federal da Paraíba, Brasil

E-mail: perazzo63@gmail.com

Ricardo Romão Guerra

ORCID: https://orcid.org/0000-0001-8226-8606 Universidade Federal da Parába, Brasil

E-mail: rromaoguerra@gmail.com

Patrícia Emília Naves Givisiez

ORCID: https://orcid.org/0000-0002-2480-1780 Universidade Federal da Paraíba, Brasil

E-mail: patriciagivisiez@gmail.com

Jalceyr Pessoa de Figueiredo Júnior

ORCID: https://orcid.org/0000-0002-2044-1247

Universidade Federal da Paraíba, Brasil

E-mail: peudure@hotmail.com

Marcelo Helder Medeiros Santana

ORCID: https://orcid.org/0000-0002-4578-5716

Instituto Federal da Paraíba, Brasil

E-mail: marcelo.santana@ifpb.edu.br

Leonilson da Silva Dantas

ORCID: https://orcid.org/0000-0001-6455-1694

Universidade Federal da Paraíba, Brasil

E-mail: leodantaszoo@hotmail.com

Lavosier Enéas Cavalcante

ORCID: https://orcid.org/0000-0001-9076-6410

Universidade Federal da Paraíba, Brasil

E-mail: lavosierzoo@gmail.com

Rafael Barbosa de Souza

ORCID: https://orcid.org/0000-0003-0803-1939 Universidade Federal da Paraíba, Brasil E-mail: rafaelbsouza@msn.com

Danilo Vargas Gonçalves Vieira

ORCID: https://orcid.org/0000-0002-7407-9597

Universidade Federal do Tocantins, Brasil

E-mail: danilovargaszoo@hotmail.com

Danilo Teixeira Cavalcante

ORCID: https://orcid.org/0000-0001-8102-3738

Universidade Federal do Agreste de Pernambuco, Brasil

E-mail: danilo.cavalcante@ufape.edu.br

Anilma Sampaio Cardoso

ORCID: https://orcid.org/0000-0002-8494-2032

Universidade Federal do Sul da Bahia, Brasil E-mail: anilma5@hotmail.com

Matheus Ramalho de Lima

ORCID: https://orcid.org/0000-0002-9897-6209

Universidade Federal do Sul da Bahia, Brasil

E-mail: mrlmatheus@gmail.com 


\begin{abstract}
Resumo
Objetivou-se determinar o nível de energia metabolizável (EM) e metionina + cistina digestível (dMetCys) para poedeiras leves nas fases de 1 a 6 semanas e de 7 a 12 semanas de idade. O delineamento experimental foi inteiramente casualizado, distribuído em esquema fatorial com 3 níveis de dMetCys $(0,576 \%, 0,640 \%$ e 7,04\% na fase de 1 a 6 semanas de idade e $0,447 \%, 0,497 \%$ e 0,547\%) x 3 níveis de EM $(2.755 ; 2.900$ e $3.045 \mathrm{kcal} / \mathrm{kg})$, totalizando 9 tratamentos. Analisou-se dados de desempenho, sorológicos e histomorfometria do intestino delgado. Na fase de 1 a 6 semanas, a combinação de 0,640\% de dMetCys com $2.755 \mathrm{kcal} / \mathrm{kg}$ de EM, assim como 0,704\% dMetCys associados a $3.045 \mathrm{kcal} / \mathrm{kg}$ de EM promoveram melhores resultados, demostrando que maior nível de dMetCys indica maior demanda de EM. As variáveis de abate e analises sorológicas mostraram-se mais satisfatórias com o nível de 0,640\% de dMetCys associada a $2.755 \mathrm{kcal} / \mathrm{kg}$ de EM. Para a fase de 7 a 12 semanas não foram observados efeitos estatísticos para as variáveis de desempenho, porém houve maior peso absoluto para fígado e baço nas dietas com maior EM, e maior peso absoluto da Bursa de Fabricius no tratamento com menores níveis de dMetCys e EM. Não ocorreu esteatose hepática em nenhuma das fases estudadas. Recomenda-se 0,640\% dMetCys associada a $2755 \mathrm{kcal} / \mathrm{kg}$ EM, nas dietas de frangas entre 1 e 6 semanas de idade, e 0,447\% dMetCys associado a $2.900 \mathrm{kcal} / \mathrm{kg}$ EM na fase de crescimento (7 a 12 semanas de idade).
\end{abstract}

Palavras-chave: Balanço nutricional; Desempenho; Interação; Metionina + cistina digestível.

\begin{abstract}
The level of metabolizable energy (EM) and methionine + digestible cystine (dMetCys) was determined for light laying hens in the phases from 1 to 6 weeks and from 7 to 12 weeks of age. The experimental design was completely randomized, distributed in a factorial scheme with 3 levels of dMetCys $(0.576 \%, 0.640 \%$ and $7.04 \%$ in the phase from 1 to 6 weeks of age and $0.447 \%, 0.497 \%$ and $0.547 \%)$ x 3 levels of MS $(2,755 ; 2,900$ and 3,045 kcal / kg), totaling 9 treatments. Performance data, serological data and histomorphometry of the small intestine were analyzed. In the 1 -to6-week phase, the combination of $0.640 \%$ dMetCys with 2,755 kcal / kg of MS, as well as $0.704 \%$ dMetCys associated with 3,045 kcal / kg of MS promoted better results, showing that a higher level of dMetCys indicates greater demand for IN. The slaughter variables and serological analyzes were more satisfactory with the level of $0.640 \%$ of dMetCys associated with 2,755 kcal / kg of ME. For the 7-to-12-week phase, no statistical effects were observed for the performance variables, but there was a higher absolute weight for liver and spleen in diets with higher MS, and a higher absolute weight for Fabricius Bursa in the treatment with lower levels of dMetCys and IN. There was no hepatic steatosis in any of the studied phases. $0.640 \%$ dMetCys associated with $2755 \mathrm{kcal} / \mathrm{kg}$ EM is recommended for chickens between 1 and 6 weeks of age, and $0.447 \%$ dMetCys associated with 2,900 kcal / kg EM during the growth phase (7 to 12 weeks of age).
\end{abstract}

Keywords: Nutritional balance; Performance; Interaction; Methionine + cystine digestible.

\title{
Resumen
}

Se determinó el nivel de energía metabolizable (EM) y metionina + cistina digestible (dMetCys) para gallinas ponedoras ligeras en las fases de 1 a 6 semanas y de 7 a 12 semanas de edad. El diseño experimental fue completamente aleatorizado, distribuido en un esquema factorial con 3 niveles de dMetCys $(0.576 \%, 0.640 \%$ y $7.04 \%$ en la fase de 1 a 6 semanas de edad y $0.447 \%, 0.497 \%$ y $0.547 \%)$ x 3 niveles de MS $(2.755 ; 2.900$ y $3.045 \mathrm{kcal} / \mathrm{kg})$, totalizando 9 tratamientos. Se analizaron los datos de rendimiento, los datos serológicos y la histomorfometría del intestino delgado. En la fase de 1 a 6 semanas, la combinación de $0.640 \%$ dMetCys con $2.755 \mathrm{kcal} / \mathrm{kg}$ de MS, así como $0.704 \%$ de dMetCys asociado con $3.045 \mathrm{kcal} / \mathrm{kg}$ de MS promovió mejores resultados, demostrando que un nivel más alto de dMetCys indica mayor demanda para IN. Las variables de sacrificio y los análisis serológicos fueron más satisfactorios con el nivel de $0,640 \%$ de dMetCys asociado a $2.755 \mathrm{kcal} / \mathrm{kg}$ de EM. Para la fase de 7 a 12 semanas, no se observaron efectos estadísticos para las variables de rendimiento, pero hubo un mayor peso absoluto para hígado y bazo en las dietas con mayor SM, y un mayor peso absoluto para Fabricius Bursa en el tratamiento con niveles más bajos de dMetCys e IN. No hubo esteatosis hepática en ninguna de las fases estudiadas. Se recomienda 0,640\% de dMetCys asociado con $2755 \mathrm{kcal} / \mathrm{kg}$ EM para pollos entre 1 y 6 semanas de edad, y 0,447\% de dMetCys asociado con 2,900 $\mathrm{kcal} / \mathrm{kg}$ EM durante la fase de crecimiento (7 a 12 semanas de edad).

Palabras clave: Equilibrio nutricional; Rendimiento; Interacción; Metionina + cistina digestible.

\section{Introdução}

Os aminoácidos sulfurosos exercem atividades fundamentais no desempenho e maturidade das frangas, pois eles são capazes de regular a expressão de numerosos genes, com isso controlar o metabolismo dos nutrientes, as funções celulares e a síntese proteica (Tesseraud et al., 2009).

A metionina é um aminoácido essencial limitante para o desempenho das aves de produção alimentadas com dietas à base de milho e farelo de soja, devendo ser suplementada nas dietas nos níveis adequados para cada fase produtiva. 
A metionina está diretamente relacionada com o crescimento das aves, pois este aminoácido é utilizado para deposição de músculos e penas, exercendo importantes funções como doadora de grupos metil (Simon, 1999), participando da síntese de glutationa (Piovacari et al., 2008), como doadora de enxofre (Wu \& Davis, 2005) e na síntese da cisteína e da S-adenosilmetionina (SAM), sendo esta responsável pelas metilações para a biossíntese de uma gama de compostos celulares, como a carnitina, creatina, proteínas e fosfolipídeos (Stipanuk, 2004). Entretanto, o excesso de metionina tende a promover redução da ingestão do alimento pelo animal.

A metionina é metabolicamente ligada à cistina, via ciclo de transsulfuração unidirecional, e a cistina pode ser sintetizada a partir da metionina e o reverso não acontece. O enxofre necessário para a biossíntese da cisteína provém do aminoácido essencial metionina (Stipanuk, 2004). Portanto, a metionina pode atender a necessidade total de aminoácidos sulfurados, sendo que a via da transsulfuração envolve ainda a síntese da homocisteína.

A cistina é essencial para a constituição das penas e pele, além de estimular o sistema hematopoiético e promove a formação de glóbulos brancos e vermelhos, colaborando com o processo de cicatrização, minimizando a dor causada pela inflamação e colabora com a formação de tecido conjuntivo (Reis, 2009).

Além do cuidado com a exigência proteica das dietas, outro fator de suma importância está relacionado com o consumo de energia, o qual também deve ser estimulado para que a ave não apresente menor peso corporal quando atingir a maturidade sexual e, consequentemente, menos reservas energéticas, as quais serão imprescindíveis nos momentos mais críticos da produção (Moretti, 1992).

A exigência de energia das poedeiras está condicionada a fatores como peso corporal, ganho de peso, produção de massa de ovos, nível de empenamento, temperatura ambiente, composição corporal e do ovo e eficiência de utilização dos nutrientes da dieta para deposição em tecido corporal e no ovo (Faria \& Santos, 2005).

Segundo Moura et al. (2008), a redução da densidade energética mantendo constante a relação energia metabolizável x nutrientes deve ser utilizada quando a finalidade é consumo, peso de ovo, ganho de peso e viabilidade para codornas japonesas em postura.

Diante disso, objetivou-se com este trabalho determinar a relação energia metabolizável: metionina + cistina digestível para aves de reposição leves nas fases de 1 a 6 semanas e de 7 a 12 semanas de idade.

\section{Metodologia}

A pesquisa foi realizada no Setor de Avicultura do Departamento de Zootecnia da Universidade Federal da Paraíba, Areia - PB. Os experimentos tiveram duração de 126 dias, divididos em duas fases de produção: inicial ( 1 a 6 semanas de idade) e cria (7 a 12 semanas de idade). As condições ambientais de temperatura e umidade relativa do ar foram registradas diariamente e as temperaturas mínima, máxima e média registradas foram de $25^{\circ}, 30^{\circ}$ e $26^{\circ} \mathrm{C}$, respectivamente. A umidade relativa média neste período foi de $87 \%$.

Os tratamentos consistiram em nove dietas, sendo uma dieta formulada para atender às exigências de todos os nutrientes, segundo as recomendações de Rostagno et al. (2011) (Tratamento 5). Para os demais tratamentos foram estabelecidas proporções dos níveis de energia metabolizável e metionina +cistina (Tabela 1).

O delineamento experimental foi inteiramente casualizado, distribuído em esquema fatorial com 3 níveis de dMetCys x 3 níveis de EM, totalizando 9 tratamentos com seis repetições de quinze aves por unidade experimental. Durante todo o período experimental as aves receberam água e ração à vontade e foram debicadas aos dez dias de idade e na décima semana de vida. Os programas de vacinação e luz adotados foram os sugeridos pelo desafio sanitário da região e manual da linhagem, respectivamente. As aves foram alojadas em boxes experimentais de 1,0 x 1,5 m, com o piso coberto com bagaço de cana. Já na fase de 7 a 12 semanas, as aves foram alojadas em gaiolas. 
Tabela 1. Desenho das dietas experimentais.

\begin{tabular}{ccc}
\hline \multirow{2}{*}{ Recomendações } & Níveis de dMetCys $(\%)$ & $\begin{array}{c}\text { Níveis de energia metabolizável } \\
(\mathrm{kcal} / \mathrm{kg})\end{array}$ \\
\hline & & $95 \%(\mathrm{~T} 1)$ \\
$100 \%(\mathrm{~T} 2)$ & $105 \%(\mathrm{~T} 3)$ \\
& $90 \%$ & $95 \%(\mathrm{~T} 4)$ \\
\cline { 2 - 3 } & & $100 \%(\mathrm{~T} 5)$ \\
& & $105 \%(\mathrm{~T} 6)$ \\
\hline
\end{tabular}

Fonte: Autores.

Na fase de 1 a 6 semanas de idade foram utilizadas 1080 aves da linhagem Dekalb White com peso vivo inicial de 38 g. As dietas foram estabelecidas com níveis de energia metabolizável de $(2.755 ; 2.900$ e $3.045 \mathrm{kcal} / \mathrm{kg})$ e níveis de metionina + cistina de $(0,576 \% ; 0,640 \%$ e $0,704 \%)$ (Tabela 2$)$.

Tabela 2. Composição e níveis nutricionais das dietas para aves de 1 a 6 semanas de idade.

\begin{tabular}{|c|c|c|c|c|c|c|c|c|c|}
\hline Ingredientes & 1 & 2 & 3 & 4 & 5 & 6 & 7 & 8 & 9 \\
\hline Milho & 61.856 & 66.405 & 65.749 & 61.758 & 66.307 & 65.691 & 61.661 & 67.624 & 65.632 \\
\hline Farelo soja & 29.310 & 28.943 & 26.049 & 29.318 & 28.951 & 26.059 & 29.326 & 26.676 & 26.069 \\
\hline Inerte & 5.229 & 1.066 & 1.895 & 5.254 & 1.092 & 1.895 & 5.280 & 1.895 & 1.895 \\
\hline Fosfato Bicálcico & 1.810 & 1.793 & 1.824 & 1.810 & 1.794 & 1.825 & 1.810 & 1.810 & 1.825 \\
\hline Calcário & 1.062 & 1.071 & 1.070 & 1.062 & 1.071 & 1.070 & 1.062 & 1.073 & 1.070 \\
\hline Bicarbonato Sódio & 0.317 & 0.319 & 0.305 & 0.317 & 0.319 & 0.305 & 0.317 & 0.303 & 0.305 \\
\hline DL-Metionina & 0.05 & 0.039 & 0.074 & 0.114 & 0.104 & 0.138 & 0.178 & 0.189 & 0.202 \\
\hline Sal & 0.192 & 0.189 & 0.200 & 0.192 & 0.189 & 0.200 & 0.192 & 0.200 & 0.200 \\
\hline L-Lisina $\mathrm{HCl}$ & 0.000 & 0.000 & 0.075 & 0.000 & 0.000 & 0.075 & 0.000 & 0.055 & 0.075 \\
\hline Óleo soja & 0.000 & 0.000 & 2.584 & 0.000 & 0.000 & 2.569 & 0.000 & 0.000 & 2.554 \\
\hline Cloreto de colina & 0.070 & 0.070 & 0.070 & 0.070 & 0.070 & 0.070 & 0.070 & 0.070 & 0.070 \\
\hline Premix Mineral & 0.050 & 0.050 & 0.050 & 0.050 & 0.050 & 0.050 & 0.050 & 0.050 & 0.050 \\
\hline Premix Vitamínico & 0.025 & 0.025 & 0.025 & 0.025 & 0.025 & 0.025 & 0.025 & 0.025 & 0.025 \\
\hline Bacitracina Zinco & 0.015 & 0.015 & 0.015 & 0.015 & 0.015 & 0.015 & 0.015 & 0.015 & 0.015 \\
\hline Antioxidante & 0.010 & 0.010 & 0.010 & 0.010 & 0.010 & 0.010 & 0.010 & 0.010 & 0.010 \\
\hline Anticoccidiostático & 0.005 & 0.005 & 0.005 & 0.005 & 0.005 & 0.005 & 0.005 & 0.005 & 0.005 \\
\hline Total & 100 & 100 & 100 & 100 & 100 & 100 & 100 & 100 & 100 \\
\hline \multicolumn{10}{|c|}{ Composição química calculada } \\
\hline Proteína Bruta, $\%$ & 18.88 & 18.117 & 17.949 & 18.913 & 18.15 & 17.886 & 18.946 & 18.349 & 17.924 \\
\hline ME, kcal/kg & 2755 & 2900 & 3045 & 2755 & 2900 & 3045 & 2755 & 2900 & 3045 \\
\hline Cálcio, \% & 0.940 & 0.940 & 0.940 & 0.940 & 0.940 & 0.940 & 0.940 & 0.940 & 0.940 \\
\hline Fósforo disp., \% & 0.437 & 0.437 & 0.437 & 0.437 & 0.437 & 0.437 & 0.437 & 0.437 & 0.437 \\
\hline ArgDig., $\%$ & 0.937 & 0.937 & 0.937 & 0.937 & 0.937 & 0.937 & 1.159 & 1.096 & 1.069 \\
\hline Lis Dig., \% & 0.876 & 0.876 & 0.876 & 0.876 & 0.876 & 0.876 & 0.876 & 0.876 & 0.876 \\
\hline Ile Dig., \% & 0,604 & 0,604 & 0,604 & 0,604 & 0,604 & 0,604 & 0,724 & 0,689 & 0,672 \\
\hline Met Dig, \% & 0,318 & 0,313 & 0,329 & 0,382 & 0,377 & 0,393 & 0,447 & 0,451 & 0,457 \\
\hline dMetCys, \% & 0.576 & 0.576 & 0.576 & 0.640 & 0.640 & 0.640 & 0.704 & 0.704 & 0.704 \\
\hline TreoDig., \% & 0.587 & 0.587 & 0.587 & 0.587 & 0.587 & 0.587 & 0.587 & 0.587 & 0.587 \\
\hline TripDig., \% & 0.158 & 0.158 & 0.158 & 0.158 & 0.158 & 0.158 & 0.158 & 0.158 & 0.158 \\
\hline Val Dig., \% & 0.666 & 0.666 & 0.666 & 0.666 & 0.666 & 0.666 & 0.666 & 0.666 & 0.666 \\
\hline Sódio, \% & 0,180 & 0,180 & 0,180 & 0,180 & 0,180 & 0,180 & 0,180 & 0,180 & 0,180 \\
\hline Cloro, \% & 0,160 & 0,160 & 0,165 & 0,160 & 0,160 & 0,165 & 0,160 & 0,166 & 0,165 \\
\hline Potássio, \% & 0,792 & 0,777 & 0,734 & 0,792 & 0,797 & 0734 & 0,791 & 0,752 & 0,734 \\
\hline
\end{tabular}

Ração formulada com base em aminoácidos digestíveis. Premix mineral inorgânico por kg de produto: Mn, 20 g; Fe, 10 g; Zn, 13 ,7 g; Cu, 2,5 g; Se, 0,063 g; I, 0,19 g; e veículo q.s.p., 500 g. Premix vitamínico por kg de ração: Vit. A - 15.000.000 Ul, Vit. D3 - 1.500.000 Ul, Vit. E $15.000 \mathrm{Ul}$, Vit.B1 - 2,0 g, Vit.B2-4,0 g, Vit B6 - 3,0 g,Vit.B12 - 0,015 g, Ácido nicotínico - $25 \mathrm{~g}$, Ácido pantotênico- $10 \mathrm{~g}$, Vit.K3 - 3,0 g, Ácido fólico- 1,0 g, Bacitracina de zinco - $10 \mathrm{~g}$, Selênio - $250 \mathrm{mg} .4$ Antioxidante BHT - $10 \mathrm{~g}$, e veículo. q.s.p. - 1.000 g. Fonte: Autores. 
No período de 7 a 12 semanas de idade, foram utilizados 3 níveis de energia metabolizável (2.755;2.900 e $3.045 \mathrm{kcal} / \mathrm{kg})$ e 3 níveis de metionina + cistina $(0,447 \% ; 0,497 \%$ e 0,547\%) (Tabela 3).

Tabela 3. Composição e níveis nutricionais das dietas para aves de 7 a 12 semanas de idade.

\begin{tabular}{|c|c|c|c|c|c|c|c|c|c|}
\hline Ingredientes & 1 & 2 & 3 & 4 & 5 & 6 & 7 & 8 & 9 \\
\hline Milho & 68.529 & 68.529 & 68.529 & 68.529 & 68.529 & 68.529 & 68.529 & 68.529 & 68.529 \\
\hline Farelo Soja & 14.252 & 14.252 & 14.252 & 14.252 & 14.252 & 14.252 & 14.252 & 14.252 & 14.252 \\
\hline Inerte & 8.499 & 4.642 & 8.785 & 8,528 & 4,616 & 8.759 & 8,555 & 4,589 & 8.732 \\
\hline Farelo trigo & 3.573 & 4.397 & 3.573 & 3,573 & 4,425 & 3.573 & 3,573 & 4,453 & 3.573 \\
\hline Fosfato bicálcico & 1.673 & 3.573 & 1.673 & 1.673 & 3,573 & 1.673 & 1,673 & 3,573 & 1.673 \\
\hline Calcário & 0.944 & 1.673 & 0.944 & 0.944 & 1.673 & 0.944 & 0.944 & 1.673 & 0.944 \\
\hline Carbonato de potássio & 0.785 & 0.944 & 0.785 & 0,785 & 0,944 & 0.785 & 0,785 & 0.944 & 0.785 \\
\hline Amido & 0.500 & 0.785 & 0.360 & 0.473 & 0.785 & 0.360 & 0.447 & 0.785 & 0.360 \\
\hline Sal & 0.360 & 0.360 & 0.294 & 0.360 & 0.360 & 0.322 & 0.360 & 0.360 & 0.350 \\
\hline L ácido glutâmico & 0.300 & 0.260 & 0.220 & 0.248 & 0.208 & 0.200 & 0.200 & 0.200 & 0.200 \\
\hline Óleo de soja & 0.200 & 0.200 & 0.200 & 0.200 & 0.200 & 0.168 & 0.196 & 0.174 & 0.174 \\
\hline DL-metionina & 0.137 & 0.137 & 0.137 & 0.137 & 0.137 & 0.137 & 0.174 & 0.156 & 0.137 \\
\hline $\mathrm{L}$ lisina $\mathrm{HCl}$ & 0.073 & 0.073 & 0.073 & 0.123 & 0.123 & 0.123 & 0.137 & 0.137 & 0.116 \\
\hline Cloreto de Colina & 0.070 & 0.070 & 0.070 & 0.070 & 0.070 & 0.070 & 0.070 & 0.070 & 0.070 \\
\hline Premix Mineral & 0.050 & 0.050 & 0.050 & 0.050 & 0.050 & 0.050 & 0.050 & 0.050 & 0.050 \\
\hline Premix Vitamínico & 0.025 & 0.025 & 0.025 & 0.025 & 0.025 & 0.025 & 0.025 & 0.025 & 0.025 \\
\hline Bacitracina de Zinco & 0.015 & 0.015 & 0.015 & 0.015 & 0.015 & 0.015 & 0.015 & 0.015 & 0.015 \\
\hline Antioxidante & 0.010 & 0.010 & 0.010 & 0.010 & 0.010 & 0.010 & 0.010 & 0.010 & 0.010 \\
\hline Anticoccidiostático & 0.005 & 0.005 & 0.005 & 0.005 & 0.005 & 0.005 & 0.005 & 0.005 & 0.005 \\
\hline Total & 100 & 100 & 100 & 100 & 100 & 100 & 100 & 100 & 100 \\
\hline \multicolumn{10}{|c|}{ Composição química calculada } \\
\hline Proteína Bruta, \% & 12.91 & 12.91 & 12.91 & 12.91 & 12.91 & 12.91 & 12.91 & 12.91 & 12.91 \\
\hline $\mathrm{ME}, \mathrm{kcal} / \mathrm{kg}$ & 2755 & 2900 & 3045 & 2755 & 2900 & 3054 & 2755 & 2900 & 3045 \\
\hline Cálcio, \% & 0.832 & 0.832 & 0.832 & 0.832 & 0.832 & 0.832 & 0.832 & 0.832 & 0.832 \\
\hline Fósforo disponível, \% & 0.392 & 0.392 & 0.392 & 0.392 & 0.392 & 0.392 & 0.392 & 0.392 & 0.392 \\
\hline Arg Dig., $\%$ & 0.718 & 0.718 & 0.718 & 0.718 & 0.718 & 0.718 & 0.718 & 0.718 & 0.718 \\
\hline Ile Dig. $\%$ & 0,451 & 0,451 & 0,451 & 0,451 & 0,451 & 0,451 & 0,451 & 0,451 & 0,451 \\
\hline Lis Dig., \% & 0.621 & 0.621 & 0.621 & 0.621 & 0.621 & 0.621 & 0.621 & 0.621 & 0.621 \\
\hline DMetCys, \% & 0,447 & 0.447 & 0.447 & 0.497 & 0.497 & 0.497 & 0.547 & 0.547 & 0.547 \\
\hline Treo Dig., \% & 0.422 & 0.422 & 0.422 & 0.422 & 0.422 & 0.422 & 0.422 & 0.422 & 0.422 \\
\hline Trip Dig., \% & 0.124 & 0.124 & 0.124 & 0.124 & 0.124 & 0.124 & 0.124 & 0.124 & 0.124 \\
\hline Val Dig., \% & 0.526 & 0.526 & 0.526 & 0.526 & 0.526 & 0.526 & 0.526 & 0.526 & 0.526 \\
\hline Sódio, \% & 0,160 & 0,160 & 0,160 & 0,160 & 0,160 & 0,160 & 0,160 & 0,160 & 0,160 \\
\hline Cloro, \% & 0,302 & 0,302 & 0,302 & 0,302 & 0,302 & 0,302 & 0,302 & 0,302 & 0,302 \\
\hline Potássio, \% & 0,936 & 0,936 & 0,936 & 0,936 & 0,936 & 0,936 & 0,936 & 0,936 & 0,936 \\
\hline Ac. Linoléico & 1,574 & 1,574 & 1,574 & 1,574 & 1,574 & 1,574 & 1,574 & 1,574 & 1,574 \\
\hline $\mathrm{FB}, \%$ & 2,501 & 2,501 & 2,501 & 2,501 & 2,501 & 2,501 & 2,501 & 2,501 & 2,501 \\
\hline
\end{tabular}

Ração formulada com base em aminoácidos digestíveis. Premix mineral inorgânico por kg de produto: Mn, 20 g; Fe, 10 g; Zn, 13,7 g; Cu, 2,5 g; Se, 0,063 g; I, 0,19 g; e veículo q.s.p., 500 g. Premix vitamínico por kg de ração: Vit. A - 15.000.000 Ul, Vit. D3 - 1.500.000 Ul, Vit. E $15.000 \mathrm{Ul}$, Vit.B1 - 2,0 g, Vit.B2-4,0 g, Vit B6 - 3,0 g,Vit.B12 - 0,015 g, Ácido nicotínico - $25 \mathrm{~g}$, Ácido pantotênico- $10 \mathrm{~g}$, Vit.K3 - 3,0 g, Ácido fólico- 1,0 g, Bacitracina de zinco - 10 g, Selênio - 250 mg.4Antioxidante BHT - 10 g, e veículo. q.s.p. - 1.000 g. Fonte: Autores.

As variáveis estudadas foram o peso vivo final (g/ave), ganho de peso (g/ave), consumo de ração (g/ave), conversão alimentar (g/g), consumo de metionina+cistina (mg/ave/dia), mensuração do peso sem vísceras (g/ave), fígado (g/ave), baço (g/ave) e gordura celomática (g/ave), além das análises sorológicas da alanina aminotransferase (U/L), aspartato aminotransferase (U/L), gamma-glutamiltransferase (U/L), creatinina (mg/dL), albumina (g/dL), proteína sérica (g/dL) e glicose (g/dL).Além disso, foi realizada a análise do soro para quantificar ácido úrico sérico (g/dL). Para as avaliações do soro destes animais foi utilizado cada Kit específico da Biotécnica®.

No último dia de cada fase experimental foram abatidas dez aves por parcela para o procedimento das análises sorológicas e histomorfométricas, além da mensuração dos órgãos. As análises sorológicas foram determinadas através do 
equipamento BS120 MINDRAY Chemistry Analyzer®.

Para as análises histomorfométricas, fragmentos do aparelho digestivo (intestino e fígado) foram imersos em solução fixadora de metacarn (metanol 60\%, clorofórmio 30\% e ácido acético 10\%) por 12 horas, realizando o procedimento histológico padrão.

Para a microscopia óptica, os fragmentos foram incluídos em paraplast e posteriormente seccionados em séries de $5 \mu \mathrm{m}$ de espessura. Os seguintes métodos de coloração histológica foram realizados: hematoxilina e eosina, ácido periódico de Schiff (PAS) e tricrômico de Masson. As fotomicrografias foram capturadas com microcâmera acoplada a microscópio Olympus BX51, e as imagens digitalizadas no software KS 400.3 (Zeiss).

As análises estatísticas das características avaliadas foram realizadas no software SAS (SAS, 2011). As médias foram comparadas pelo teste de Tukey, a 5\% de probabilidade.

\section{Resultados e Discussão}

\section{Fase Inicial - 1 a 6 semanas de idade}

Houve efeito estatístico $(\mathrm{P}<0,05)$ quanto aos níveis de energia metabolizável de dMetCys nas variáveis de desempenho (Tabela 4). O peso vivo final e o ganho de peso foram influenciados pelos tratamentos, com melhores resultados observados com 0,640\% dMetCys e $2.755 \mathrm{kcal} / \mathrm{kg}$, e 0,704\% dMetCys com $3.045 \mathrm{kcal} / \mathrm{kg}$, respectivamente.

Os dados de peso final e ganho mostram que a dMetCys e a EM estão intimamente ligados e diretamente proporcionais. Os resultados podem ser justificados devido à intensa síntese proteica nesta fase de desenvolvimento, pois há grande exigência dos aminoácidos para a biossíntese na velocidade exigida pelo organismo animal e sabe-se que a metionina vem sendo considerada como sendo o aminoácido mais versátil nas vias metabólicas da transulfuração e remetilação, tornando-se o aminoácido iniciador na síntese de todas as proteínas eucarióticas, por isso pode ser considerado o aminoácido limitante mais importante na nutrição avícola (Baker, 2009; Brosnan \& Brosnan, 2006; Khosravi, 2015).

Observou-se diminuição no consumo de ração $(\mathrm{P}<0,05)$ das aves alimentadas com dietas as quais foram compostas pelos maiores níveis de energia metabolizável. Isso pode ter ocorrido devido a diminuição na ingestão de energia que as aves realizam para ajustar às exigências de mantença de acordo com a temperatura ambiente para que haja uma possível redução da produção de calor corporal englobando o calor produzido durante o processo de digestório (Guimarães et al., 2014).

Os efeitos quanto a conversão alimentar apresentados, não foram piorados nos tratamentos dietéticos de alta energia porque a redução do ganho de peso não foi suficiente para alterar a proporção consumo de ração/ ganho de peso. Porém, provavelmente se tornarão carcaças mais magras, uma vez que as enzimas lipogênicas estão reduzidas nesta situação, podendo haver uma tendência ao acúmulo de gordura abdominal. 
Tabela 4. Efeitos da interação entre metionina + cistina digestível e energia metabolizável sobre os dados de desempenho das aves de 1 a 6 semanas de idade.

\begin{tabular}{|c|c|c|c|c|c|c|c|c|c|}
\hline \multirow[t]{2}{*}{ Variável } & \multirow[t]{2}{*}{$\begin{array}{c}\text { dMetCys } \\
(\%)\end{array}$} & \multicolumn{3}{|c|}{$\begin{array}{l}\text { Energia Metabolizável } \\
(\text { EM kcal/kg) }\end{array}$} & \multirow[t]{2}{*}{ Média } & \multirow[t]{2}{*}{$\mathrm{CV}, \%$} & \multirow[t]{2}{*}{ dMetCys } & \multirow[t]{2}{*}{ SEM } & \multirow[t]{2}{*}{$\begin{array}{c}\text { dMetCys* } \\
\text { EM }\end{array}$} \\
\hline & & 2755 & 2900 & 3045 & & & & & \\
\hline \multirow{3}{*}{ Peso Final, g } & 0,576 & 608 & 621 & 623 & 617 & \multirow{3}{*}{5.09} & \multirow{3}{*}{0.0422} & \multirow{3}{*}{0.2999} & \multirow{3}{*}{0.0158} \\
\hline & 0,640 & $619 a$ & $583 \mathrm{ab}$ & $570 \mathrm{~b}$ & 591 & & & & \\
\hline & 0,704 & $603 \mathrm{ab}$ & $579 \mathrm{~b}$ & $626 \mathrm{a}$ & 603 & & & & \\
\hline Média & & 610 & 594 & 606 & & & & & \\
\hline \multirow{3}{*}{ Ganho Peso, g } & 0,576 & 570 & 583 & 585 & 579 & \multirow{3}{*}{5.43} & \multirow{3}{*}{0.0422} & \multirow{3}{*}{0.2999} & \multirow{3}{*}{0.0158} \\
\hline & 0,640 & $581 \mathrm{a}$ & $545 \mathrm{ab}$ & $532 \mathrm{~b}$ & 553 & & & & \\
\hline & 0,704 & $565 \mathrm{ab}$ & $541 \mathrm{~b}$ & $588 \mathrm{a}$ & 565 & & & & \\
\hline Média & & 572 & 556 & 568 & & & & & \\
\hline \multirow{3}{*}{$\begin{array}{l}\text { Consumo } \\
\text { Ração, g }\end{array}$} & 0,576 & 1.113 & 1.117 & 1.121 & $1.117 \mathrm{a}$ & \multirow{3}{*}{4.23} & \multirow{3}{*}{0.0003} & \multirow{3}{*}{$<.0001$} & \multirow{3}{*}{$<.0001$} \\
\hline & 0,640 & $1.113 \mathrm{ab}$ & $1.163 \mathrm{~b}$ & $1.071 \mathrm{a}$ & $1.117 \mathrm{a}$ & & & & \\
\hline & 0,704 & $1.320 \mathrm{~b}$ & $1.113 \mathrm{a}$ & $1.100 \mathrm{a}$ & $1.180 \mathrm{~b}$ & & & & \\
\hline Média & & $1.239 \mathrm{~b}$ & $1.134 \mathrm{ab}$ & $1.109 \mathrm{a}$ & & & & & \\
\hline \multirow{3}{*}{$\begin{array}{l}\text { Conversão } \\
\text { Alimentar, g/g }\end{array}$} & 0,576 & 1.953 & 1.916 & 1.916 & $1.929 \mathrm{a}$ & \multirow{3}{*}{7.35} & \multirow{3}{*}{0.0003} & \multirow{3}{*}{$<.0001$} & \\
\hline & 0,640 & $1.916 \mathrm{a}$ & $2.134 \mathrm{~b}$ & $2.013 \mathrm{~b}$ & $2.020 \mathrm{ab}$ & & & & $<.0001$ \\
\hline & 0,704 & $2.336 \mathrm{~b}$ & $2.057 \mathrm{a}$ & $1.871 \mathrm{a}$ & $2.088 \mathrm{~b}$ & & & & \\
\hline Média & & $2.170 \mathrm{~b}$ & $2.039 \mathrm{~b}$ & $1.952 \mathrm{a}$ & & & & & \\
\hline & 0,576 & $323 a$ & $255 \mathrm{~b}$ & $264 \mathrm{ab}$ & 281 & & & & \\
\hline $\begin{array}{l}\text { Peso } \\
\text { Corno }\end{array}$ & 0,640 & 292 & 301 & 244 & 279 & 20.22 & 0.7889 & 0.0004 & 0.1003 \\
\hline & 0,704 & $337 \mathrm{a}$ & $258 \mathrm{~b}$ & $271 \mathrm{~b}$ & 289 & & & & \\
\hline Média & & $317 \mathrm{a}$ & $271 \mathrm{~b}$ & $260 \mathrm{~b}$ & & & & & \\
\hline Peso corporal & 0,576 & $258 \mathrm{a}$ & $202 \mathrm{~b}$ & $209 \mathrm{ab}$ & 223 & & & & \\
\hline sem vísceras, & 0,640 & 231 & 237 & 192 & 220 & 21.30 & 0.8776 & 0.0004 & 0.1239 \\
\hline$g$ & 0,704 & $267 \mathrm{a}$ & $201 \mathrm{~b}$ & $210 \mathrm{~b}$ & 226 & & & & \\
\hline Média & & $252 \mathrm{a}$ & $213 \mathrm{~b}$ & $203 \mathrm{~b}$ & & & & & \\
\hline & 0,576 & 8.9 & 7.6 & 7.7 & 8.1 & & & & \\
\hline Fígado g & 0,640 & $9.5 \mathrm{a}$ & $9.4 \mathrm{ab}$ & $7.5 \mathrm{~b}$ & 8.8 & 21.20 & 0.2053 & 0.0013 & 0.1272 \\
\hline & 0,704 & $10.3 \mathrm{a}$ & $7.7 \mathrm{~b}$ & $8.5 \mathrm{ab}$ & 8.8 & & & & \\
\hline Média & & $9.5 \mathrm{a}$ & $8.2 \mathrm{~b}$ & $7.9 \mathrm{~b}$ & & & & & \\
\hline & 0,576 & $0.833 \mathrm{a}$ & $0.587 \mathrm{~b}$ & $0.595 \mathrm{ab}$ & 0.671 & & & & \\
\hline Baço, $g$ & 0,640 & 0.743 & 0.678 & 0.542 & 0.654 & 33.19 & 0.496 & 0.0002 & 0.3461 \\
\hline & 0,704 & $0.919 \mathrm{a}$ & $0.573 \mathrm{~b}$ & $0.672 \mathrm{~b}$ & 0.721 & & & & \\
\hline Média & & $0.832 \mathrm{a}$ & $0.613 \mathrm{~b}$ & $0.603 \mathrm{~b}$ & & & & & \\
\hline
\end{tabular}

*Letras minúsculas diferem entre as linhas, Teste de Tukey a 5\% de probabilidade. Fonte: Dados dos autores (2021).

Efeitos significativos $(\mathrm{P}<0,05)$ foram observados para pesos da carcaça eviscerada, assim como para peso de fígado e baço. Neste estudo, os maiores pesos do fígado encontram-se nos tratamentos com $2.755 \mathrm{kcal} / \mathrm{kg}$ de EM associado a $0,640 \%$ e 0,704\% dMetCys. O baço assim como o peso da ave eviscerado, apresentou os maiores resultados nos tratamentos com $2.755 \mathrm{kcal} / \mathrm{kg}$ de EM e $5,76 \%$ e $0,704 \%$ dMetCys.

De acordo com Carew et al. (2003), o peso do fígado pode estar relacionado com a deficiência de metionina causa aumento no tamanho do fígado de aves, provavelmente devido o aumento no teor de gordura. Apesar de apresentar os menores pesos nos tratamentos com 5,76 \% de dMetCys, os resultados demonstraram que não houve deficiência deste nutriente em nenhum dos tratamentos estudados. Acioli (2012) afirma, que o crescimento dos órgãos do trato digestório e a melhoria do sistema imunológico necessita que haja o desenvolvimento normal das aves. Entretanto o fígado nas aves é considerado o órgão mais relevante porque centraliza o metabolismo geral alterando seu peso e atividades metabólicas. Sabe-se que o desequilíbrio dos nutrientes pode acarretar uma sobrecarga dos órgãos.

A avaliação da relação dos diferentes níveis de aminoácidos sulfurosos e energia metabolizável encontrou efeitos significativos $(\mathrm{P}<0,05)$ nos valores de todas as variáveis sorológicas apresentados (Tabela 5). Os níveis de aminoácidos na dieta 
podem modificar a repartição de nutrientes na corrente sanguínea e por isso, alterar os níveis de glicose, proteínas, albumina e creatinina no plasma. A determinação das enzimas transaminases, proteína total, creatinina plasmática e albumina, podem expressar intervenção metabólica associada a compostos nitrogenados segundo Jardim Filho et al. (2010).

A presença em maiores níveis da alanina aminotransferase foram observadas nas aves as quais consumiram a maior quantidade de ração, o que explicaria estas taxas, devido a maior quantidade de aminoácidos ingerido, necessitando assim de uma maior atividade da ALT (alanina aminotransferase), a qual necessita estar envolvida no catabolismo dos aminoácidos, justificando a elevação desta enzima no sangue dessas aves.

Sabe-se que em condições fisiológicas, a enzima GGT, assim como a AST Tabela 5, são encontradas em baixos níveis no plasma sanguíneo e em altas concentrações no interior dos hepatócitos. Desta maneira, ao observar aumento da atividade sérica destas enzimas, pode-se relacionar com alterações teciduais com aumento de permeabilidade das membranas plasmáticas e liberação das enzimas para o soro (Kaneko, 1997). O aumento da excreção de ácido úrico nas aves foi observado em conformidade ao aumento dos níveis de dMetCys, sabe-se que manter a ideal relação aminoacídica nas dietas diminui o aumento da excreção dos mesmos, e isto promoveria menor utilização de energia para excreção do excesso da proteína ingerida pelo animal.

Tabela 5. Interação dos efeitos entre metionina + cistina digestível e energia metabolizável, sobre as variáveis sorológicas das poedeiras com idades de 1 a 6 semanas de idade.

\begin{tabular}{|c|c|c|c|c|c|c|c|c|c|}
\hline \multirow[t]{2}{*}{ Variáveis } & \multirow[t]{2}{*}{$\begin{array}{c}\text { dMetCys } \\
(\%)\end{array}$} & \multicolumn{3}{|c|}{ Energia Metabolizável (kcal/kg) } & Média & \multirow[t]{2}{*}{$\mathrm{CV}, \%$} & \multirow[t]{2}{*}{ dMetCys } & \multirow[t]{2}{*}{ SEM } & \multirow[t]{2}{*}{$\begin{array}{c}\text { dMetCys* } \\
\text { EM }\end{array}$} \\
\hline & & 2.755 & 2.900 & & 45 & & & & \\
\hline \multirow{3}{*}{$\mathrm{ALT}, \mathrm{U} / \mathrm{L}$} & 0,576 & $27.70 \mathrm{~b}$ & $23.00 \mathrm{c}$ & $33.20 \mathrm{a}$ & $24.83 \mathrm{ab}$ & \multirow{4}{*}{14.12} & \multirow{4}{*}{$<.0001$} & \multirow{4}{*}{0.0006} & \multirow{4}{*}{0.1438} \\
\hline & 0,640 & $79.30 \mathrm{a}$ & $32.70 \mathrm{~b}$ & $16.10 \mathrm{c}$ & $23.17 \mathrm{~b}$ & & & & \\
\hline & 0,704 & $16.20 \mathrm{~b}$ & $34.30 \mathrm{a}$ & $32.30 \mathrm{a}$ & $26.37 \mathrm{a}$ & & & & \\
\hline \multirow[t]{2}{*}{ Média } & & $23.03 \mathrm{~b}$ & $26.67 \mathrm{a}$ & $24.67 \mathrm{ab}$ & & & & & \\
\hline & 0,576 & $149.70 \mathrm{a}$ & $131.60 \mathrm{~b}$ & $144.60 \mathrm{a}$ & $250.20 \mathrm{a}$ & \multirow{4}{*}{19.85} & \multirow{4}{*}{$<.0001$} & \multirow{4}{*}{0.1668} & \multirow{4}{*}{0.096} \\
\hline \multirow{2}{*}{ AST, U/L } & 0,640 & $252.30 \mathrm{a}$ & $166.20 \mathrm{~b}$ & $135.80 \mathrm{c}$ & $231.77 \mathrm{a}$ & & & & \\
\hline & 0,704 & $135.70 \mathrm{c}$ & $167.10 \mathrm{a}$ & $147.30 \mathrm{~b}$ & $187.30 \mathrm{~b}$ & & & & \\
\hline \multirow[t]{2}{*}{ Média } & & 215.77 & 235.67 & 217.83 & & & & & \\
\hline & 0,576 & $15.40 \mathrm{a}$ & $15.30 \mathrm{a}$ & $13.10 \mathrm{~b}$ & $29.53 \mathrm{a}$ & \multirow{4}{*}{10.39} & \multirow{4}{*}{0.0374} & \multirow{4}{*}{0.0039} & \multirow{4}{*}{0.7511} \\
\hline \multirow{3}{*}{ GGT, U/L } & 0,640 & 15.50 & 15.30 & 16.60 & $27.10 \mathrm{~b}$ & & & & \\
\hline & 0,704 & $10.20 \mathrm{~b}$ & $15.90 \mathrm{a}$ & $15.70 \mathrm{a}$ & $24.63 \mathrm{c}$ & & & & \\
\hline & & $27.43 \mathrm{a}$ & $28.13 \mathrm{a}$ & $25.70 \mathrm{~b}$ & & & & & \\
\hline \multirow{4}{*}{$\begin{array}{l}\text { Albumina, } \\
\text { g/dL } \\
\text { Média }\end{array}$} & 0,576 & 1.67 & 1.66 & 1.52 & 1.62 & \multirow{4}{*}{10.53} & \multirow{4}{*}{0.0374} & & \\
\hline & 0,640 & 1.68 & 1.69 & 1.51 & 1.63 & & & 0.0083 & 0.0017 \\
\hline & 0,704 & $1.54 \mathrm{~b}$ & $1.86 \mathrm{a}$ & $1.77 \mathrm{a}$ & 1.72 & & & & \\
\hline & & $1.63 \mathrm{ab}$ & $1.74 \mathrm{a}$ & $1.60 \mathrm{~b}$ & & & & & \\
\hline & 0,576 & 3.64 & 3.65 & 3.36 & $3.55 \mathrm{a}$ & & & & \\
\hline frotena iotal, & 0,640 & $3.69 \mathrm{a}$ & $3.70 \mathrm{a}$ & $3.22 \mathrm{~b}$ & $3.54 \mathrm{a}$ & 8.69 & 0.0006 & 0.0047 & 0.0037 \\
\hline & 0,704 & 3.09 & 3.37 & 3.36 & $3.27 \mathrm{~b}$ & & & & \\
\hline Média & & $3.47 \mathrm{ab}$ & $3.57 \mathrm{a}$ & $3.31 \mathrm{~b}$ & & & & & \\
\hline & 0,576 & $0.180 \mathrm{~b}$ & $0.230 \mathrm{a}$ & $0.200 \mathrm{ab}$ & 0.273 & & & & \\
\hline Creatinina, g/L & 0,640 & $0.150 \mathrm{a}$ & $0.180 \mathrm{a}$ & $0.100 \mathrm{~b}$ & 0.277 & 16.29 & 0.0076 & 0.4801 & 0.7473 \\
\hline & 0,704 & 0.200 & 0.200 & 0.190 & 0.263 & & & & \\
\hline Média & & 0.273 & 0.277 & 0.263 & & & & & \\
\hline & 0,576 & 275 & 280.1 & 279.5 & $278.20 \mathrm{a}$ & & & & \\
\hline $\begin{array}{l}\text { Gicose, } \\
\mathrm{U} / \mathrm{L}\end{array}$ & 0,640 & $270.8 \mathrm{a}$ & $257.4 \mathrm{ab}$ & $243.2 \mathrm{~b}$ & $257.13 \mathrm{~b}$ & 8.85 & 0.0039 & 0.0883 & $<.0001$ \\
\hline & 0,704 & $232.7 \mathrm{~b}$ & $275.3 \mathrm{a}$ & $292.4 \mathrm{a}$ & $266.80 \mathrm{ab}$ & & & & \\
\hline Média & & 259.5 & 270.93 & 271.7 & & & & & \\
\hline & 0,576 & 3.54 & 3.23 & 3.68 & $3.48 \mathrm{c}$ & & & & \\
\hline umol/L & 0,640 & $3.55 \mathrm{c}$ & $4.62 \mathrm{~b}$ & $5.77 \mathrm{a}$ & $4.65 \mathrm{~b}$ & 12.13 & $<.0001$ & $<.0001$ & $<.0001$ \\
\hline & 0,704 & $6.51 \mathrm{a}$ & $4.66 \mathrm{~b}$ & $6.69 \mathrm{a}$ & $5.95 \mathrm{a}$ & & & & \\
\hline Média & & $4.53 \mathrm{~b}$ & $4.17 \mathrm{~b}$ & $5.38 \mathrm{a}$ & & & & & \\
\hline
\end{tabular}


* As letras minúsculas diferem entre as colunas, pelo teste de Tukey a 5\% de probabilidade. Fonte: Dados dos autores (2021).

Para histomorfometria do intestino delgado das aves foram encontrados valores com diferenças significativas $(\mathrm{P}<0,05)$ nas dietas associadas a 0,576\% dMetCys com os diferentes níveis de energia metabolizável, para as variáveis largura de vilosidades e profundidade de cripta, entretanto a relação vilosidade: cripta não foi significativamente alterada nos tratamentos (Tabela 6).

A altura das vilosidades intestinais e da profundidade da cripta está diretamente relacionada com a capacidade absortiva dos animais e, por sua vez, o aumento na altura de vilosidade pode ocorrer devido a maior proliferação das células na cripta. É sabido que, durante o estresse térmico por calor as aves reduzem o consumo de ração, na tentativa de diminuir a produção do calor endógeno (Lin et al., 2006), resultando em danos na morfologia e integridade intestinal, comprometendo os mecanismos de digestão e absorção e, consequentemente, reduzindo o desempenho das aves.

Tabela 6. Interação dos efeitos entre metionina + cistina digestível e energia metabolizável, na histomorfologia intestinal das aves com idade de 1 a 6 semanas.

\begin{tabular}{|c|c|c|c|c|c|c|c|c|c|}
\hline \multirow[t]{2}{*}{ Variável } & \multirow[t]{2}{*}{$\begin{array}{c}\text { dMetCys } \\
(\%)\end{array}$} & \multicolumn{3}{|c|}{ Energia Metabolizável (kcal/kg) } & \multirow[t]{2}{*}{ Média } & \multirow[t]{2}{*}{$\mathrm{CV}, \%$} & \multirow[t]{2}{*}{ dMetCys } & \multirow[t]{2}{*}{ SEM } & \multirow[t]{2}{*}{$\begin{array}{c}\text { dMetCys } \\
\text { *EM }\end{array}$} \\
\hline & & 2.755 & 2.900 & 3.045 & & & & & \\
\hline \multirow{3}{*}{$\begin{array}{l}\text { Altura } \\
\text { Vilo } \mu \mathrm{m}\end{array}$} & 0,576 & 9637.13 & 10999.00 & 8826.58 & 9734 & \multirow{3}{*}{74.89} & \multirow{3}{*}{0.3288} & \multirow{3}{*}{0.6236} & \multirow{3}{*}{0.2942} \\
\hline & 0,640 & 9771.60 & - & 13034.00 & 11644 & & & & \\
\hline & 0,704 & 10291.00 & & 9321.97 & 9784 & & & & \\
\hline Média & & 9867 & 10990 & 10599 & & & & & \\
\hline Largura & 0,576 & $1335.21 \mathrm{a}$ & $1175.95 \mathrm{~b}$ & $1279.00 \mathrm{ab}$ & $1271.97 \mathrm{ab}$ & \multirow{3}{*}{18.04} & \multirow{3}{*}{0.0146} & \multirow{3}{*}{0.0527} & \multirow{3}{*}{0.7149} \\
\hline \multirow{2}{*}{$\begin{array}{l}\text { Vilo, } \\
\mu \mathrm{m}\end{array}$} & 0,640 & 1320.14 & - & 1326.72 & $1323.91 \mathrm{a}$ & & & & \\
\hline & 0,704 & 1224.84 & - & 1165.99 & $1194.08 \mathrm{~b}$ & & & & \\
\hline Média & & $1298.71 \mathrm{a}$ & $1175.95 \mathrm{~b}$ & $1265.00 \mathrm{ab}$ & & & & & \\
\hline \multirow{3}{*}{$\begin{array}{l}\text { Profundi } \\
\text { dade } \\
\text { Cripta, } \\
\mu \mathrm{m}\end{array}$} & 0,576 & $2590.04 \mathrm{a}$ & $1587.33 \mathrm{ab}$ & $1387.38 \mathrm{~b}$ & 1901.5 & \multirow{3}{*}{90.23} & \multirow{3}{*}{0.1467} & \multirow{3}{*}{0.1872} & \multirow{3}{*}{0.0592} \\
\hline & 0,640 & 1396.33 & - & 1521.46 & 1468.2 & & & & \\
\hline & 0,704 & 1542.29 & - & 1509.46 & 1525.1 & & & & \\
\hline Média & & 1912.5 & 1587.3 & 1474.4 & & & & & \\
\hline \multirow{3}{*}{$\begin{array}{l}\text { Vilos: } \\
\text { Cripta }\end{array}$} & 0,576 & 6.075 & 7.215 & 7.208 & 6.778 & \multirow{3}{*}{105.35} & \multirow{3}{*}{0.08} & \multirow{3}{*}{0.3961} & \multirow{3}{*}{0.2035} \\
\hline & 0,640 & $7.364 \mathrm{~b}$ & - & $12.433 \mathrm{a}$ & 10.274 & & & & \\
\hline & 0,704 & 7.180 & - & 6384,00 & 6.764 & & & & \\
\hline Média & & 6.799 & 7.215 & 8.996 & & & & & \\
\hline
\end{tabular}

* As letras minúsculas diferem entre as colunas, pelo teste de Tukey a 5\% de probabilidade. Fonte: Dados dos autores (2021).

\section{Fase de crescimento - 7 a 12 semanas de idade}

Para as variáveis de desempenho não houve diferenças significativas ( $\mathrm{P}>0,05)$, para as aves com idades de 7 a 12 semanas de idades. (Tabela 7). Apesar de não ter havido interação estatística entre os aminoácidos sulfurosos e os níveis de energia, pode-se notar que as dietas com o maior nível energético foram consumidas em menor proporção, avaliação feita numericamente. Isto pode ter ocorrido devido a fase de desenvolvimento destas aves, em que a necessidade de energia e nutrientes não é tão alta para a formação de tecidos, mas para que possam amadurecer órgãos reprodutivos e acumular reservas para a estação reprodutiva. 
Tabela 7. Efeitos da interação entre metionina + cistina digestível e energia metabolizável sobre os parâmetros de desempenho das aves de 7 a 12 semanas de idade.

\begin{tabular}{|c|c|c|c|c|c|c|c|c|c|}
\hline Variável & $\begin{array}{c}\text { dMetCys } \\
(\mathrm{g} / \mathrm{kg})\end{array}$ & \multicolumn{3}{|c|}{$\begin{array}{c}\text { Energia Metabolizável } \\
(\mathrm{kcal} / \mathrm{kg})\end{array}$} & Média & $\mathrm{CV}, \%$ & dMetCys & SEM & $\begin{array}{l}\text { dMetCys } \\
\text { *EM }\end{array}$ \\
\hline \multirow{4}{*}{ Peso Inicial, $\mathrm{g}$} & & 2.755 & 2.900 & 3.045 & & \multirow{4}{*}{2,9} & \multirow{4}{*}{0,9960} & \multirow{4}{*}{0,9988} & \multirow{4}{*}{1,0000} \\
\hline & 0,447 & 558 & 557 & 558 & 557 & & & & \\
\hline & 0,497 & 557 & 557 & 557 & 557 & & & & \\
\hline & 0,547 & 557 & 558 & 558 & 557 & & & & \\
\hline Média & & 557 & 557 & 557 & & & & & \\
\hline \multirow{3}{*}{ Peso final, $\mathrm{g}$} & 0,447 & 922 & 930 & 924 & 925 & \multirow{3}{*}{1,2} & \multirow{3}{*}{0,7523} & \multirow{3}{*}{0,0954} & \multirow{3}{*}{0,3925} \\
\hline & 0,497 & 917 & 927 & 934 & 926 & & & & \\
\hline & 0,547 & 924 & 921 & 941 & 929 & & & & \\
\hline Média & & 921 & 926 & 933 & & & & & \\
\hline \multirow{3}{*}{ Ganho Peso, g } & 0,447 & 364 & 372 & 367 & 368 & \multirow{3}{*}{5,75} & \multirow{3}{*}{0,9331} & \multirow{3}{*}{0,4905} & \multirow{3}{*}{0,8575} \\
\hline & 0,497 & 360 & 370 & 377 & 369 & & & & \\
\hline & 0,547 & 367 & 363 & 384 & 371 & & & & \\
\hline Média & & 364 & 368 & 376 & & & & & \\
\hline \multirow{3}{*}{$\begin{array}{c}\text { Consumo Ração, } \\
\text { g }\end{array}$} & 0,447 & 1,132 & 1,107 & 1,203 & 1,147 & \multirow{3}{*}{4,17} & \multirow{3}{*}{0,434} & \multirow{3}{*}{0,0318} & \multirow{3}{*}{0,3198} \\
\hline & 0,497 & 1,165 & 1,120 & 1,137 & 1,141 & & & & \\
\hline & 0,547 & 1,095 & 1,092 & 1,171 & 1,119 & & & & \\
\hline Média & & $1,131 \mathrm{ab}$ & $1,106 \mathrm{a}$ & $1,171 \mathrm{~b}$ & & & & & \\
\hline \multirow{3}{*}{$\begin{array}{c}\text { Conversão } \\
\text { Alimentar, g/g }\end{array}$} & 0,447 & 3,11 & 2,980 & 3,28 & 3,117 & \multirow{3}{*}{7,92} & \multirow{3}{*}{0,488} & \multirow{3}{*}{0,6044} & \multirow{3}{*}{0,7188} \\
\hline & 0,497 & 3,24 & 3,03 & 3,02 & 3,092 & & & & \\
\hline & 0,547 & 2,98 & 3,01 & 3,05 & 3,016 & & & & \\
\hline Média & & 3,107 & 3,005 & 3,114 & & & & & \\
\hline
\end{tabular}

* As letras minúsculas diferem entre as colunas, pelo teste de Tukey a 5\% de probabilidade. Fonte: Dados dos autores (2021).

Nas variáveis peso dos órgãos foi observada interação $(\mathrm{P}<0,05)$ dos fatores para as variáveis fígado, baço e bursa. Sendo que o peso encontrado para a bursa diminuiu conforme a oferta de dMetCys e EM na dieta de frangas em crescimento. Isso pode ser explicado pelo baixo fornecimento de nutrientes essenciais para a síntese de proteínas, como dMetCys e energia, que alterou o sistema imunológico da ave, e fez com que a bursa tivesse intensa atividade celular (Wu, 2013), pois a bursa de fabricius é o órgão linfóide primário, responsável pela produção e manutenção do compartimento de células B em espécies de aves (Hengmin,1988; Thompson et al., 1970), (Tabela 8).

Segundo Brito et al. (2004), a maior parte dos aminoácidos são degradados no fígado, com exceção da leucina, isoleucina e valina, entretanto os aminoácidos sulfurados quando fornecidos de forma excessiva as aves, sofrem a transaminação nos hepatócitos. A presença de aminoácidos excessivos em relação às necessidades biossintéticas celular ocasiona rápida degradação (Champ et al., 2009). Esse evento gera uma série de resíduos que podem ser nocivos ao fígado, comprometendo o seu desenvolvimento (Lehninger, 1995). Porém o excesso de metionina promove maior deposição de gordura abdominal, inibição do aproveitamento da treonina e aumento no tamanho de fígado (Katz \& Baker, 1975; Mendes et al., 1993; Gous et al., 1999; Whitaker et al., 2002), mas não foi observado efeito significativo quando a gordura abdominal, o que nos permitir acreditar que não houve excesso dos aminoácidos sulfurosos. 
Tabela 8. Efeitos da interação entre metionina + cistina digestível e energia metabolizável sobre o peso dos órgãos das aves de 7 a 12 semanas de idade.

\begin{tabular}{|c|c|c|c|c|c|c|c|c|c|}
\hline \multirow[b]{2}{*}{ Variável } & \multirow{2}{*}{$\begin{array}{r}\text { dMetCy } \\
\text { s (g/kg) }\end{array}$} & \multicolumn{3}{|c|}{ Energia Metabolizável (kcal/kg) } & \multirow[b]{2}{*}{ Média } & \multicolumn{3}{|c|}{$\mathrm{Met}+\mathrm{Cy}$} & \multirow{2}{*}{$\begin{array}{c}\mathrm{Met}+\mathrm{Cy} \\
\mathrm{s}^{*} \mathrm{ME}\end{array}$} \\
\hline & & & & & & $\mathrm{CV}, \%$ & $\mathrm{~s}$ & SEM & \\
\hline & & 2.755 & 2.900 & 3.045 & & & & & \\
\hline \multirow{3}{*}{$\begin{array}{l}\text { Peso Corporal, } \\
\text { g }\end{array}$} & 0,447 & 962 & 973 & 958 & 965 & \multirow{4}{*}{5,69} & \multirow{4}{*}{0,7734} & \multirow{4}{*}{0,3481} & \multirow{4}{*}{0,5041} \\
\hline & 0,497 & 944 & 964 & 996 & 968 & & & & \\
\hline & 0,547 & 970 & 969 & 984 & 975 & & & & \\
\hline Média & & 959 & 969 & 980 & & & & & \\
\hline \multirow{3}{*}{$\begin{array}{l}\text { Peso corporal } \\
\text { sem visceras, } g\end{array}$} & 0,447 & 789 & 801 & 782 & 791 & \multirow{4}{*}{5,86} & \multirow{4}{*}{0,4447} & \multirow{4}{*}{0,4701} & \multirow{4}{*}{0,2550} \\
\hline & 0,497 & 783 & 794 & 832 & 803 & & & & \\
\hline & 0,547 & 804 & 803 & 808 & 805 & & & & \\
\hline \multirow[t]{2}{*}{ Média } & & 792 & 799 & 807 & & & & & \\
\hline & 0,447 & 0,2146 & 0,2228 & 0,2315 & 0,223 & \multirow{4}{*}{10,58} & \multirow{4}{*}{0,9806} & \multirow{4}{*}{0,0181} & \multirow{4}{*}{0,5241} \\
\hline \multirow[t]{2}{*}{ Fígado, g } & 0,497 & $0,2054 \mathrm{~b}$ & $0,2333 \mathrm{a}$ & $0,2305 \mathrm{ab}$ & 0,2231 & & & & \\
\hline & 0,547 & 0,2201 & 0,2235 & 0,2286 & 0,2241 & & & & \\
\hline \multirow[t]{2}{*}{ Média } & & $0,2134 \mathrm{~b}$ & $0,2265 \mathrm{ab}$ & $0,2302 \mathrm{a}$ & & & & & \\
\hline & 0,447 & 0,02104 & 0,02142 & 0,02304 & 0,02183 & \multirow{4}{*}{14,74} & \multirow{4}{*}{0,5005} & \multirow{4}{*}{0,0223} & \multirow{4}{*}{0,1917} \\
\hline \multirow[t]{2}{*}{ Baço, g } & 0,497 & $0,01907 \mathrm{~b}$ & $0,02024 \mathrm{~b}$ & $0,02361 \mathrm{a}$ & 0,02097 & & & & \\
\hline & 0,547 & 0,02154 & 0,02043 & 0,02115 & 0,02104 & & & & \\
\hline Média & & $0,02055 \mathrm{~b}$ & $0,02070 \mathrm{ab}$ & $0,02260 \mathrm{a}$ & & & & & \\
\hline \multirow{3}{*}{$\begin{array}{c}\text { Gordura } \\
\text { Abdominal, g }\end{array}$} & 0,447 & 0,1640 & 0,1584 & 0,1433 & 0,1552 & \multirow{4}{*}{41,57} & \multirow{4}{*}{0,7319} & & \\
\hline & 0,497 & 0,1229 & 0,1625 & 0,1503 & 0,1453 & & & 0,4814 & 0,7453 \\
\hline & 0,547 & 0,1342 & 0,1557 & 0,1409 & 0,1436 & & & & \\
\hline Média & & 0,1404 & 0,1589 & 0,1448 & & & & & \\
\hline & 0,447 & $0,02555 \mathrm{a}$ & $0,01861 \mathrm{~b}$ & $0,01570 \mathrm{~b}$ & 0,01995 & & & & \\
\hline Bursa, g & 0,497 & 0,01584 & 0,01476 & 0,01667 & 0,01576 & 22,54 & 0,0005 & 0,1044 & $<.0001$ \\
\hline & 0,547 & 0,01681 & 0,02029 & 0,01914 & 0,01875 & & & & \\
\hline Média & & 0,0194 & 0,01789 & 0,01717 & & & & & \\
\hline
\end{tabular}

* As letras minúsculas diferem entre as colunas, pelo teste de Tukey a 5\% de probabilidade. Fonte: Dados dos autores (2021).

De acordo com D'Agostini (2005) no decorrer da fase de crescimento é primordial fornecer nutrientes para atender às exigências de manutenção e crescimento, garantindo assim o bom desenvolvimento do sistema imunológico, estrutural corporal, e reprodutivo, proporcionando máxima produtividade na fase de postura.

O baço é um órgão que possui primordial função imunológica na produção de anticorpos. Os resultados encontrados no presente estudo diferem dos observados por Pinheiro et al., 2020, que ao trabalhar com aves com idades de 24 a 44 semanas de idade e níveis de dMetCys de 0,603; 0,607 e 0,737\% e níveis de EM de 2.755, 2.900 e 3.045 kcal/kg; não observaram diferença do tamanho do baço. Esta diferença entre os resultados encontrados, pode estar relacionado a idade das aves. Pois segundo Acioli (2012), o desenvolvimento dos órgãos do sistema imunológico assim como do trato digestório, estão relacionados ao desenvolvimento normal das aves na fase inicial.

Os parâmetros sorológicos sofreram influência $(\mathrm{P}<0,05)$ quanto aos níveis de aminoácidos sulfurosos e energia metabolizável (Tabela 9). Os resultados superiores em sua maioria apresentaram quando houve a interação do nível de 0,447\% dMetCys. e 2.755 EM. Os níveis de glicose estão relacionados ao fato de a metionina ser um aminoácido glicogênico, que após a desaminação que produz o $\alpha$-cetoácidosuccinil-CoA, o qual seguira para formação do piruvato. Posterior, o piruvato pode ser utilizado no ciclo do ácido cítrico, produzindo energia, ou poderá ser utilizado na via da gliconeogênese, recuperando moléculas de glicose (Nelson \& Cox, 2011).

Níveis baixos de aminoácidos e proteínas na alimentação das aves tem sido associado à regressão da proteína sérica total e à albumina (Emadi et al. 2010). Assim como citado anteriormente consideram-se as enzimas GGT e AST, devem apresentar-se em menores níveis no plasma sanguíneo, o aumento desta atividade sérica possivelmente estar ligado a mudanças 
teciduais com aumento da permeabilidade das membranas plasmáticas e liberação de enzimas para o soro (Kaneko, 1997).

Tabela 9. Interação dos efeitos entre metionina + cistina digestível e energia metabolizável, sobre os parâmetros sorológicos das poedeiras com idades de 7 a 12 semanas de idade.

\begin{tabular}{|c|c|c|c|c|c|c|c|c|c|}
\hline \multirow[t]{2}{*}{ Variável } & \multirow[t]{2}{*}{$\begin{array}{c}\text { dMetCys } \\
(\mathrm{g} / \mathrm{kg})\end{array}$} & \multicolumn{3}{|c|}{ Energia Metabolizável (kcal/kg) } & \multirow[t]{2}{*}{ Média } & \multirow[t]{2}{*}{$\mathrm{CV}, \%$} & \multirow[t]{2}{*}{ dMetCys } & \multirow[t]{2}{*}{ SEM } & \multirow[t]{2}{*}{ dMetCys *EM } \\
\hline & & 2.755 & 2.900 & 3.045 & & & & & \\
\hline \multirow{3}{*}{ ALT, U/L } & 0,447 & $14.80 \mathrm{a}$ & $7.80 \mathrm{~b}$ & $6.60 \mathrm{c}$ & 9.73 & \multirow{3}{*}{5.09} & \multirow{3}{*}{$<.0001$} & \multirow{3}{*}{$<.0001$} & \multirow{3}{*}{$<.0001$} \\
\hline & 0,497 & $7.00 \mathrm{c}$ & $8.30 \mathrm{~b}$ & $10.20 \mathrm{a}$ & 8.5 & & & & \\
\hline & 0,547 & $10.10 \mathrm{~b}$ & $10.80 \mathrm{a}$ & $8.50 \mathrm{c}$ & 9.8 & & & & \\
\hline Média & & $10.63 \mathrm{a}$ & $8.97 \mathrm{~b}$ & $8.43 \mathrm{~b}$ & & & & & \\
\hline \multirow{3}{*}{ AST, U/L } & 0,447 & $150.70 \mathrm{~b}$ & $157.20 \mathrm{a}$ & $147.90 \mathrm{c}$ & $151.93 \mathrm{~b}$ & \multirow{3}{*}{0.68} & \multirow{3}{*}{$<.0001$} & \multirow{3}{*}{$<.0001$} & \multirow{3}{*}{$<.0001$} \\
\hline & 0,497 & $148.10 \mathrm{c}$ & $156.60 \mathrm{~b}$ & $160.50 \mathrm{a}$ & $155.07 \mathrm{a}$ & & & & \\
\hline & 0,547 & $145.40 \mathrm{a}$ & $141.20 \mathrm{c}$ & $142.50 \mathrm{~b}$ & $143.03 \mathrm{c}$ & & & & \\
\hline Média & & $148.07 \mathrm{~b}$ & $151.67 \mathrm{a}$ & $150.30 \mathrm{ab}$ & & & & & \\
\hline \multirow{3}{*}{ GGT, U/L } & 0,447 & $31.00 \mathrm{a}$ & $24.70 \mathrm{~b}$ & $25.00 \mathrm{~b}$ & $26.90 \mathrm{a}$ & \multirow{3}{*}{3.89} & \multirow{3}{*}{$<.0001$} & \multirow{3}{*}{$<.0001$} & \multirow{3}{*}{$<.0001$} \\
\hline & 0,497 & $25.40 \mathrm{~b}$ & $27.30 \mathrm{a}$ & $23.70 \mathrm{c}$ & $25.47 \mathrm{a}$ & & & & \\
\hline & 0,547 & $24.20 \mathrm{~b}$ & $13.30 \mathrm{c}$ & $30.30 \mathrm{a}$ & $22.60 \mathrm{~b}$ & & & & \\
\hline Média & & $26.87 \mathrm{a}$ & $21.77 \mathrm{~b}$ & $26.33 \mathrm{a}$ & & & & & \\
\hline \multirow{3}{*}{$\begin{array}{l}\text { Albumina, } \\
\text { g/dL }\end{array}$} & 0,447 & $2.20 \mathrm{a}$ & $1.78 \mathrm{c}$ & $2.07 \mathrm{~b}$ & $2.02 \mathrm{~b}$ & \multirow{3}{*}{2.44} & \multirow{3}{*}{$<.0001$} & \multirow{3}{*}{$<.0001$} & \\
\hline & 0,497 & $2.05 \mathrm{~b}$ & $2.10 \mathrm{ab}$ & $2.15 \mathrm{a}$ & $2.10 \mathrm{a}$ & & & & $<.0001$ \\
\hline & 0,547 & $2.02 \mathrm{~b}$ & $2.13 \mathrm{a}$ & $2.00 \mathrm{~b}$ & $2.05 \mathrm{ab}$ & & & & \\
\hline Média & & $2.09 \mathrm{a}$ & $2.00 \mathrm{~b}$ & $2.07 \mathrm{ab}$ & & & & & \\
\hline & 0,447 & $4.08 \mathrm{~b}$ & $3.70 \mathrm{c}$ & $4.82 \mathrm{a}$ & 4.20 & & & & \\
\hline Proteing $\alpha / I$ & 0,497 & $4.48 \mathrm{a}$ & $4.36 \mathrm{~b}$ & $4.21 \mathrm{c}$ & 4.35 & 2.4 & $<.0001$ & $<.0001$ & $<.0001$ \\
\hline & 0,547 & 4.24 & 4.24 & 4.18 & 4.22 & & & & \\
\hline Média & & $4.27 \mathrm{ab}$ & $4.10 \mathrm{~b}$ & $4.40 \mathrm{a}$ & & & & & \\
\hline & 0,447 & $0.30 \mathrm{~b}$ & $0.38 \mathrm{a}$ & $0.30 \mathrm{~b}$ & $0.33 \mathrm{a}$ & & & & \\
\hline Creatınına, & 0,497 & 0.30 & 0.30 & 0.30 & $0.30 \mathrm{a}$ & 19.66 & $<.0001$ & 0.0092 & 0.0202 \\
\hline & 0,547 & $0.15 \mathrm{~b}$ & $0.20 \mathrm{ab}$ & $0.21 \mathrm{a}$ & $0.12 \mathrm{~b}$ & & & & \\
\hline Média & & $0.250 \mathrm{~b}$ & $0.293 \mathrm{a}$ & $0.270 \mathrm{ab}$ & & & & & \\
\hline & 0,447 & $289.80 \mathrm{a}$ & $222.30 \mathrm{~b}$ & $289.30 \mathrm{a}$ & $267.13 \mathrm{a}$ & & & & \\
\hline Glicose,U/L & 0,497 & $281.90 \mathrm{a}$ & $251.00 \mathrm{c}$ & $260.60 \mathrm{~b}$ & $264.50 \mathrm{a}$ & 0.71 & $<.0001$ & $<.0001$ & $<.0001$ \\
\hline & 0,547 & $253.70 \mathrm{~b}$ & $241.20 \mathrm{c}$ & $269.70 \mathrm{a}$ & $254.87 \mathrm{~b}$ & & & & \\
\hline Média & & $275.13 \mathrm{a}$ & $238.17 \mathrm{~b}$ & $273.20 \mathrm{a}$ & & & & & \\
\hline & 0,447 & $4.14 \mathrm{~b}$ & $3.09 \mathrm{c}$ & $4.33 \mathrm{a}$ & $3.85 \mathrm{~b}$ & & & & \\
\hline Acido Urico, & 0,497 & $3.04 \mathrm{c}$ & $4.15 \mathrm{~b}$ & $5.46 \mathrm{a}$ & $4.22 \mathrm{ab}$ & 3.97 & $<.0001$ & $<.0001$ & $<.0001$ \\
\hline & 0,547 & $6.01 \mathrm{a}$ & $3.88 \mathrm{~b}$ & $3.52 \mathrm{c}$ & $4.47 \mathrm{a}$ & & & & \\
\hline Média & & $4.40 \mathrm{a}$ & $3.71 \mathrm{~b}$ & $4.44 \mathrm{a}$ & & & & & \\
\hline
\end{tabular}

* As letras minúsculas diferem entre as colunas, pelo teste de Tukey a 5\% de probabilidade. Fonte: Dados dos autores (2021).

Segundo Safdari-Rostamabad et al. (2017), o estresse térmico por calor pode reduziu a concentração de proteínas totais. Os autores atribuem esse fato a uma possível redução na digestibilidade dos nutrientes em condições de estresse térmico, é sabido que houve altas temperaturas no decorrer desta pesquisa, o que explicaria possivelmente os resultados apresentados.

Análises da histomorfologia intestinal são apresentadas na Tabela 10, os quais apresentaram efeitos estatísticos ( $\mathrm{P}<$ 0,05) para altura e largura de vilo apenas. Obtendo resultados superiores nos níveis de 0,447\% de dMetCys e 2.900 EM e níveis de 0,497 \% dMetCys. e 2.900 EM, respectivamente. Sabe-se que vilos mais largos tende a possuírem mais ramificações, as quais permitem ter uma área de superfície para maior absorção de nutrientes.

É desejável que as criptas não sejam demasiadamente profundas, indicando com isso uma absorção mais eficiente, os resultados apresentados demonstram estatisticamente que os níveis dos aminoácidos sulfurosos bem como da energia metabolizável, não exerceram influência negativa sobre esta variável.

A profundidade da cripta pode apontar o nível de hiperplasia das células intestinais; uma vez que a diminuição da 
profundidade demonstra menor nível de agressão à morfologia da parede intestinal (Hancock et al., 1990). A relação vilo x cripta, também não apresentou influência estatística, mas sabe-se que quanto maior esta relação, maior é a absorção dos nutrientes (Arruda et al., 2008).

Tabela 10. Interação dos efeitos entre metionina + cistina digestível e energia metabolizável, na histomorfologia intestinal das aves com idade de 7 a 12 semanas.

\begin{tabular}{|c|c|c|c|c|c|c|c|c|c|}
\hline \multirow[t]{2}{*}{ Variável } & \multirow{2}{*}{$\begin{array}{l}\text { dMet } \\
\text { Cys } \\
(\mathrm{g} / \mathrm{kg})\end{array}$} & \multicolumn{3}{|c|}{ Energia Metabolizável (kcal/kg) } & \multirow[t]{2}{*}{ Média } & \multirow[t]{2}{*}{$\mathrm{CV}, \%$} & \multirow{2}{*}{$\begin{array}{c}\mathrm{dMetC} \\
\mathrm{ys}\end{array}$} & \multirow[t]{2}{*}{ SEM } & \multirow{2}{*}{$\begin{array}{l}\text { dMetC } \\
\text { ys *ME }\end{array}$} \\
\hline & & 2.755 & 2.900 & 3.045 & & & & & \\
\hline \multirow{3}{*}{ Altura Vilo. $\mu \mathrm{m}$} & 0,447 & $10,484 \mathrm{~b}$ & $12,890 \mathrm{a}$ & $11,266 \mathrm{ab}$ & $11537.5 \mathrm{~b}$ & & & & \\
\hline & 0,497 & 11,010 & 11,219 & 12,236 & $11559.6 \mathrm{~b}$ & 22.88 & 0.0002 & 0.2078 & 0.0377 \\
\hline & 0,547 & 13,433 & 12,609 & 13,909 & $13271.9 \mathrm{a}$ & & & & \\
\hline Média & & 11642.5 & 12212.6 & 12492.6 & & & & & \\
\hline \multirow{3}{*}{ Largura Vilo } & 0,447 & 1733.22 & 1632.3 & 1734.07 & $1700.97 \mathrm{a}$ & & & & \\
\hline & 0,497 & $1429.47 \mathrm{~b}$ & $1808.30 \mathrm{a}$ & $1606.08 \mathrm{ab}$ & $1625.23 \mathrm{ab}$ & 20.52 & 0.0238 & 0.0507 & 0.0218 \\
\hline & 0,547 & 1483.28 & 1636 & 1494.73 & $1545.38 \mathrm{~b}$ & & & & \\
\hline Média & & $1548.66 \mathrm{~b}$ & $1694.02 \mathrm{a}$ & $1611.39 \mathrm{ab}$ & & & & & \\
\hline \multirow{3}{*}{$\begin{array}{l}\text { Profundidade } \\
\text { Cripta. } \mu \mathrm{m}\end{array}$} & 0,447 & 2447.47 & 2426.66 & 2124.28 & 2326.1 & & & & \\
\hline & 0,497 & 2302.11 & 2320.96 & 2363.00 & 2330.7 & 25.63 & 0.4116 & 0.8625 & 0.3375 \\
\hline & 0,547 & 2363.81 & 2451.25 & 2542.59 & 2455.1 & & & & \\
\hline Média & & 2371.1 & 2399.6 & 2344.1 & & & & & \\
\hline \multirow{3}{*}{ Vilos:Cripta } & 0,447 & 4.74 & 5.75 & 5.74 & 5.42 & & & & \\
\hline & 0,497 & 5.36 & 5.04 & 5.86 & 5.43 & 39.26 & 0.7027 & 0.5446 & 0.3527 \\
\hline & 0,547 & 6.06 & 5.38 & 5.63 & 5.66 & & & & \\
\hline Média & & 5.39 & 5.38 & 5.75 & & & & & \\
\hline
\end{tabular}

* As letras minúsculas diferem entre as colunas, pelo teste de Tukey a 5\% de probabilidade. Fonte: Dados dos autores (2021).

De acordo com os autores Cera (1988) e Rioperez et al. (1991), quanto maior a altura das vilosidades e menor profundidade das criptas, maior será a absorção dos nutrientes, e consequentemente ocorrerá uma diminuição das perdas energéticas para a renovação celular; entretanto a diminuição das áreas das vilosidades promove uma menor atividade enzimática, redução na digestibilidade e absorção de nutrientes, maior predisposição a doenças entéricas ou distúrbios digestivos, como também a adesão de bactérias aos enterócitos. Portanto, fica evidente que a relação entre altura dos vilos e profundidade de cripta da mucosa intestinal representa um excelente indicador de proliferação e desenvolvimento de enterócitos nas vilosidades.

\section{Considerações Finais}

Na dieta para as aves de reposição leves entre 1 e 6 semanas de idade recomenda-se a utilização de 0,640\% de metionina + cistina digestível associado a um nível de $2.755 \mathrm{kcal} / \mathrm{kg}$ de energia metabolizável (relação EM:M + C digestível de 4304,68). A recomendação para as aves de reposição leves entre 7 e 12 semanas de idade é de 0,447\% de metionina + cistina digestível e de $2.900 \mathrm{kcal} / \mathrm{kg}$ de energia metabolizável (relação EM: M+C digestível de 6487,69).

\section{Referências}

Acioli, M. I. L. (2012). A importância da qualidade de uma franga: os fatores que influenciam o desempenho das aves desde a aquisição até a fase de crescimento. Brasil. A Revista do Ovo, n.8.

Arruda, A. M. V., Fernandes, R. T. V., da Silva, J. M., \& Lopes, D. C. (2008). Avaliação morfo-histológica da mucosa intestinal de coelhos alimentados com diferentes níveis e fontes de fibra. Revista Caatinga, 21(2), 1-11. 
Baker, D. H. (2009). Advances in protein-amino acid nutrition of poultry. Amino acids, 37, 29-41.

Brito, A. B. D., Stringhini, J. H., Café, M. B., Xavier, S. A. G., Muramatsu, K., \& Andrade, M. A. (2004). Níveis de metionina+ cistina em rações de frangos de corte na ração pré-inicial (1-7 dias). http://repositorio.bc.ufg.br/handle/ri/12962.

Brosnan, J. T., \& Brosnan, M. E. (2006). The sulfur-containing amino acids: an overview. Journal of Nutrition, 136, 1636S-1640S.

Carew, L. B., Mcmurtry, J. P., \& Alster, F. A. (2003). Effect of methionine deficiencies on plasma levels of thyroid hormones insulin-like growth factors-I and -II, liver and body weights, and feed intake in growing chickens. Poultry Science.;82, 1932-1938.

Cera, K. R., Mahan, D. C., Cross, R. F., Reinhart, G. A., \& Whitmoyer, R. E. (1988). Effect of age, weaning and post-weaning diet on small intestinal growth and jejunal morphology in young swine. Journal of Animal Science, Champaign, 66(2), 574-584.

Champ, P. C., Harvey, R. A., \& Ferrier, D. R. (2009). Bioquímica ilustrada. (4a ed.): Artmed, 528p.

Hengmin, C. (1988). The histopathologic study of selenium deficiency in chicks. Acta Veterinaria Et Zootechnica Sinica (China).

D’Agostini, P. (2005). Exigências de metionina+cistina para frangas de reposição leves e semipesadas nas fases inicial, cria e recria. 120f. Tese (Doutorado em Zootecnia) - Universidade Federal de Viçosa, Viçosa.

Emadi, M., Kaveh, K., Bejo, M. H., Ideris, A., Jahanshiri, F., Ivan, M., \& Alimon, R. A. (2010). Growth performance and blood parameters as influenced by different levels of dietary arginine in broiler chickens. Journal of Animal and Veterinary Advances, 9(1), 70-74.

Faria Domingues, C. H., Sgavioli, S., Praes, M. F. F. M., Santos, E. T., Castiblanco, D. M. C., Petrolli, T. G., \& Junqueira, O. M. (2016). Lisina e metionina+ cistina digestíveis sobre o desempenho e qualidade de ovos de poedeiras comerciais: Revisão. Pubvet, 10, 448-512.

Faria, D. E., \& Santos, A. L. (2005). Exigências nutricionais de galinhas poedeiras. Simpósio Internacional sobre Exigências Nutricionais de Aves e Suínos, 2 , 315-329.

Guimarães, M. C. D. C., Furtado, D. A., do Nascimento, J. W., Tota, L. D. C., Silva, C. M. D., \& Lopes, K. B. D. P. (2014). Efeito da estação do ano sobre o desempenho produtivo de codornas no semiárido paraibano. Revista Brasileira de Engenharia Agrícola e Ambiental, 18(2), 231-237.

Gous, R. M., Moran Jr, E. T., Stilborn, H. R., Bradford, G. D., \& Emmans, G. C. (1999). Evaluation of the parameters needed to describe the overall growth, the chemical growth, and the growth of feathers and breast muscles of broilers. Poultry Science, 78(6), 812-821.

Kaneko, J. J., Harvey, J. W., \& Bruss, M. L. (1997). Clinical Biochemistry of Domestic Animals. (5a ed.), Academic Press. 932p.

Katz, R. S., \& Baker, D. H. (1975.). Methionine toxicity in the chicks: Nutritional and metabolic implications. Journal of Nutrition, Bethesda, 105, $1168-1175$.

Khosravi, H., Mehri, M., Bagherzadeh-Kasmani, F., \& Asgharimoghadam, M. (2015). Methionine requirement of growing Japanese quails. Animal Feed Science and Technology, 212, 122-128.

Jardim Filho, R. D. M., Stringhini, J. H., Andrade, M. A., Café, M. B., Leandro, N. S. M., \& Carvalho, F. B. D. (2010). Levels of digestible lysine for Hy-Line W-36 hens in production period. Revista Brasileira de Zootecnia, 39(4), 787-795.

Lima, H. J. D., Barreto, S. L. T., Donzele, J. L., Souza, G. S., Almeida, R. L., Tinoco, I. F. F., \& Albino, L. F. T. (2016). Digestible lysine requirement for growing Japanese quais. Journal of Appllied Poultry Research, 25, 483-491.

Lin, H., Jeao, H. C., Buyse, J., \& Decuypere, E. (2006). Strategies for preventing heat stress in Poultry. World's Poultry Science Journal, Ithaca, 62(1), 71-86.

Mendes, A. A., Gonzales, E., Garcia, E. A., \& Varoli, J. C. (1993). Efeitos do nível nutricional da dieta e do sexo sobre o rendimento de carcaça de frangos de corte. Revista Brasileira de Zootecnia, Viçosa, 22(3), 473-480.

Moretti, C. S. (1992). Pontos críticos na recria e produção de poedeiras comerciais. In: Conferência Apinco de Ciência e Tecnologia Avícola, Santos.

Moura, G. D. S., Barreto, S. L. D. T., Donzele, J. L., Hosoda, L. R., Pena, G. D. M., \& Angelini, M. S. (2008). Dietas de diferentes densidades energéticas mantendo constante a relação energia metabolizável: nutrientes para codornas japonesas em postura. Revista Brasileira de Zootecnia, 37(9), 1628-1633.

Nelson, D. L., \& Cox, M. M. (2011). Princípios de Bioquímica de Lehninger: Sarvier, (5a ed.),1274p.

Pinheiro, S. G., Costa, F. G. P., Guerra, R. R., Givisiez, P. E. N., de Abreu, C. G., da Silva Dantas, L., \& Cardoso, A. S. (2020). Energia metabolizável e aminoácidos sulfurosos para poedeiras leves no primeiro ciclo de produção. Research, Society and Development, 9(8), e344984895-e344984895.

Piovacari, S. M., Shima, M., \& Cardoso, R. (2008). Imunonutrição. Enstein: Educação Continuada em Saúde, 6, 41-43.

Reis, R. S. (2009). Relação metionina mais cistina com lisina em dietas para codornas japonesas em postura. Dissertação (Universidade Federal de Viçosa), p. 1-52. https://locus.ufv.br//handle/123456789/5624.

Rioperez, J., Sanchez, C. P., \& Cantaño, M. (1991). Estudio histopatologico del ileon de lechones precozmente destetados dependiente del cereal utilizado en su alimentación. Archivos de Zootecnia, Córdoba, 40, 261-271.

Rostagno, H. S., Albino, L. F. T., Donzele, J. L., Gomes, P. C., Oliveira, R. F., Lopes, D. C., \& Euclides, P. F. (2011). Tabelas brasileiras para aves e suínos. Composição de alimentos e exigências nutricionais. (3rd ed.) UFV, Brasil.

Safdari-Rostamabad, M., Hosseini-Vashan, S. J., Perai, A. H., \& Sarir, H. (2017). Nanoselenium supplementation of heat-stressed broilers: effects on performance, carcass characteristics, blood metabolites, immune response, antioxidant status, and jejunal morphology. Biological Trace Element Research, $178(1), 105-116$. 
Research, Society and Development, v. 10, n. 4, e3110413806, 2021

(CC BY 4.0) | ISSN 2525-3409 | DOI: http://dx.doi.org/10.33448/rsd-v10i4.13806

Simon, J. (1999). Choline, betaine and methionine interactions in chickens, pigs and fish (including crustaceans). Worlds Poultry Science Journal, 55, 353-374.

Stipanuk, M. H. (2004). Sulfur amino acid metabolism: pathway for production and removal of homocysteine and cysteine. Annual Review Nutrition, 24, 539577 .

Thompson, J. N., \& Scott, M. L. (1970). Impaired lipid and vitamin E absorption related to atrophy of the pancreas in selenium-deficient chicks. Journal of Nutrition.100:797-809.

Whitaker, H. M. A., Mendes, A. A., Garcia, E. A., Roça, R. O., Varolli JR, J. C., \& Saldanha, E. P. B. (2002). Efeito da suplementação de metionina sobre o desempenho e avaliação de carcaça de frangos de corte. Brazilian Journal of Poultry Science, 4(1), 01-09.

Wu, G. (2013). Amino acids: biochemistry and nutrition: CRC Press Taylor \& Francis Group.

Wu, G., \& Davis, D. A. (2005). Interrelationship among methionine, choline and betaine in channel catfish - Ictalurus punctatus. Journal of the World Aquaculture Society, 36, 337-34.

Tesseraud, S., Coustard, S. M., Collin, A., \& Seiliez, I. (2009). Role of súlfur amino acids in controlling nutrient metabolism and cell functions: implications for nutrition. British Journal of Nutrition, 101, 1132-1139. 